\title{
Development and characterization of a preclinical ovarian carcinoma model to investigate the mechanism of acquired resistance to trastuzumab
}

\author{
LEOPOLDO L. LUISTRO ${ }^{1}$, JAMES A. ROSINSKI ${ }^{2}$, HONGJIN BIAN ${ }^{1}$, SUBAL BISHAYEE ${ }^{3}$, \\ PRANELA RAMESHWAR ${ }^{4}$, NICHOLAS M. PONZIO ${ }^{3}$ and STEVE R. RITLAND ${ }^{5,6}$ \\ ${ }^{1}$ Department of Discovery Oncology, Hoffmann-La Roche Inc.; ${ }^{2}$ Translational Research Sciences, \\ Hoffmann-La Roche Inc., Nutley, NJ 07110; ${ }^{3}$ Department of Pathology and Laboratory Medicine, University of Medicine \\ and Dentistry of New Jersey - New Jersey Medical School and Graduate School of Biomedical Sciences; \\ ${ }^{4}$ Department of Medicine - Hematology/Oncology, University of Medicine and Dentistry of New Jersey - \\ New Jersey Medical School, Newark, NJ 07101; 5 Pharma Clinical Research and \\ Exploratory Development, Hoffmann-La Roche Inc., Nutley, NJ 07110, USA
}

Received January 20, 2012; Accepted February 27, 2012

DOI: $10.3892 /$ ijo.2012.1463

\begin{abstract}
Trastuzumab (Herceptin $\left.{ }^{\circledR}\right)$ is a humanized monoclonal antibody designed to bind and inhibit the function of the human epidermal growth factor receptor 2 (HER2)/erbB2 receptor. Trastuzumab has demonstrated clinical activity in several types of HER2-overexpressing epithelial tumors, such as breast and metastatic gastric or gastroesophageal junction cancer. Relapse and therapeutic resistance, however, still occur in a subset of patients treated with regimens including trastuzumab, despite significant improvements in response rates, survival and quality of life. To investigate the potential mechanisms of acquired therapeutic resistance to trastuzumab, we developed a preclinical model of human ovarian cancer cells, SKOV-3 Herceptin-resistant (HR), and examined the corresponding changes in gene expression profiles. SKOV-3 HR cells were developed by in vivo serial passaging of parental trastuzumab-sensitive SKOV-3 cells. Following four rounds of serial transplantation of 'breakthrough' xenograft tumors under trastuzumab treatment, significant and reproducible differences in the effects of trastuzumab treatment between SKOV-3 HR and SKOV-3 cells in vivo and in vitro were revealed. SKOV-3 HR cells retained HER 2 protein expression but were unaffected by
\end{abstract}

Correspondence to: Dr Leopoldo L. Luistro, Department of Discovery Oncology, Hoffmann-La Roche Inc., 340 Kingsland Street, Building 123, 2nd Floor, Nutley, NJ 07110, USA

E-mail: leopoldo_1.luistro@roche.com

Present address: ${ }^{6}$ Celgene Corp., Summit, NJ 07901, USA

Key words: trastuzumab, Herceptin, human epidermal growth factor receptor 2, acquired resistance, ovarian cancer, microarray expression profiling, mucin1 the antiproliferative effects of trastuzumab. The trastuzumab binding affinity for SKOV-3 HR cells was diminished, despite these cells having more binding sites for trastuzumab. Microarray expression profiling (MEP) was performed to determine the genes involved in the resistance mechanism. Functional analysis revealed the differential expression of genes potentially involved in angiogenesis, metastasis, differentiation and proliferation, such as mucin1 (MUC1). Immunohistochemical staining of SKOV-3 HR cells demonstrated a marked overexpression of MUC1. Based on these data, we hypothesize that the overexpression of MUC1 may hinder trastuzumab binding to HER2 receptors, abrogating the antitumor effects of trastuzumab and thus could contribute to resistance to therapy. Moreover, the resultant MEP preclinical gene signature in this preclinical model system may provide the basis for further investigation of potential clinical mechanisms of resistance to trastuzumab.

\section{Introduction}

The erbB [human epidermal growth factor receptor (HER)] receptors are expressed in a variety of tissues of epithelial, mesenchymal and neuronal origin, in which they play fundamental roles in development, differentiation and proliferation (1). The deregulated or dysfunctional expression of the erbB receptors, in particular epidermal growth factor receptor (EGFR/erbB1/HER1) and erbB2 (HER2), has been implicated in the development and malignancy of numerous human cancers (2). The overexpression of HER2 receptors, which results from $H E R 2$ gene amplification, leads to the activation of specific receptor homodimers in the absence of a cognate soluble ligand. HER2 homodimerization and heterodimerization with the other EGFR family members (EGFR, HER3 and HER4) stimulate tyrosine kinase phosphorylation and activation of intracellular signal transduction pathways, in particular the phosphatidylino- 
sitol 3-kinase (PI3K) and mitogen-activated protein kinase (MAPK) pathways, promoting potent proliferation and cell growth (3). In breast cancers, approximately $20 \%$ of tumors show HER 2 overexpression, which is clinically associated with poor prognosis, decreased survival and shorter time to relapse at all stages $(4,5)$. In addition, patients with ovarian cancer have also been shown to overexpress HER2 (3), although the prognostic significance and incidence remain unclear. In one phase II study, 95/837 (11.4\%) patients with recurrent ovarian or primary peritoneal cancer were found to overexpress HER2 protein as defined by immunohistochemistry (IHC) $2^{+} / 3^{+}(6)$. In a separate study, HER 2 gene amplification as determined by fluorescence in situ hybridization was observed in 6/33 (18.2\%) of ovarian mucinous carcinomas (7).

The high incidence of HER2 overexpression in cancer cells and the prognostic value of HER2 in breast cancer led to the development of trastuzumab (Herceptin ${ }^{\circledR}$, Genentech, South San Francisco, CA) for the treatment of HER2-positive breast cancer in the metastatic $(8,9)$ and adjuvant settings $(10-13)$. Recently, trastuzumab plus chemotherapy was approved for the treatment of metastatic gastric and gastroesophageal cancers (14). Trastuzumab is a humanized immunoglobulin G1 monoclonal antibody that binds the HER2 extracellular domain (ECD) and inhibits growth-promoting downstream signaling (15). The efficacy of trastuzumab in the adjuvant and metastatic settings has clearly been established. In the adjuvant setting, the addition of trastuzumab to chemotherapy regimens has led to significant improvements in disease-free survival and overall survival (OS) (10-13). In metastatic breast cancer (MBC), firstline trastuzumab plus chemotherapy has been shown to improve response rates, time to progression, and OS (8), while second- or third-line trastuzumab monotherapy has been shown to produce durable objective responses for women whose tumors progress on chemotherapy (9). However, many HER2-positive breast cancers do not respond to or progress on trastuzumab treatment, suggesting that these patients may have intrinsic or developed acquired resistance to trastuzumab, respectively.

A wide range of preclinical cancer models have been developed to address resistance mechanisms that range from insulin-like growth factor 1 (IGF-1)-induced loss of $\mathrm{p} 27^{\mathrm{Kip} 1}$, loss of phosphatase and tensin homolog (PTEN) function, enhanced expression of EGFR ligands, masking of the trastuzumab-binding epitope by mucin (MUC)4, induction of tumor initiating cells by Y-box-binding protein 1, and enhanced Src activity (16-21). However, the analysis of large-scale clinical samples and rational translational research are required to establish a causal link between these proposed mechanisms and resistance to trastuzumab.

Preclinical ovarian carcinoma cell lines exhibit HER2 gene amplification and accompanying HER2 receptor overexpression. Many of these models have been used to test for the antitumor efficacy of trastuzumab. Despite promising preclinical results, however, translational activity in the clinical setting with the use of trastuzumab to treat ovarian cancer has been limited, with a low rate of objective responses in patients with HER2 overexpression observed in a phase II study (6). The reason for the observed low response rate in this tumor type is still unclear. Although many mechanistic studies of resistance have been performed in preclinical breast cancer models, obtaining data from a different tumor type, such as HER2-overexpressing ovarian carcinoma, offers an attractive alternative, enabling the outcomes to be compared and contrasted, and added to the existing knowledge base. The similarities between the HER2 oncogenic processes of HER2-positive breast and ovarian cancers are numerous and may therefore allow the results from one tumor type to be applied to another. New data from ovarian cancer models may shed light on the causes of both acquired and de novo trastuzumab resistance in breast cancer, and may provide insight into the cause of the relative lack of effectiveness of trastuzumab in patients with HER2-positive ovarian cancer. Moreover, these studies may enable the identification of pharmacodynamic biomarkers of resistance or new targets that could potentially lead to new and potent antineoplastic agents. Lastly, preclinical gene signatures resulting from microarray expression profiling (MEP) may ultimately be used to identify patients who are more likely to respond to or be resistant to trastuzumab therapy, thereby informing treatment decisions.

In this study, we used the SKOV-3 human ovarian carcinoma cell line to develop the first preclinical model of ovarian carcinoma to study acquired or de novo resistance to trastuzumab. The SKOV-3 human ovarian carcinoma cell line is one of a few distinct ovarian preclinical models with HER2 gene amplification, $185^{\mathrm{HER} 2}$ overexpression and sensitivity to the effects of trastuzumab (3). A trastuzumab-resistant variant was developed by in vivo serial passaging of trastuzumab-treated subcutaneous SKOV-3 tumors in athymic nu/nu (nude) mice with ultimate selection of SKOV-3 Herceptin-resistant (HR) 'breakthrough' variants. We characterized the SKOV-3 HR cell line by assessing the antiproliferative and antitumor effects of trastuzumab on the cells both in vitro and in vivo, by examining HER2 expression and number of trastuzumab binding sites, and by determining the trastuzumab binding affinity for these cells, comparing these results with those obtained in the parental SKOV-3 cell line. In addition, we performed MEP of the SKOV-3 HR and parental cell lines to identify any differential gene expression between the two cell lines that could potentially contribute to the mechanism of resistance to trastuzumab therapy that the SKOV-3 HR cell line exhibits.

\section{Materials and methods}

Cells and antibodies. SKOV-3 cells were purchased from the American Type Culture Collection (Manassas, VA, USA). MDA-MB-435 cells were obtained from Dr Janet Price (MD Anderson Cancer Center, Houston, TX, USA). Cells were cultured in appropriate medium with $10 \%$ heat-inactivated fetal bovine serum (FBS) and $2 \mathrm{mM}$ L-glutamine. All cell culture materials were purchased from Invitrogen/Gibco (Grand Island, NY, USA). Trastuzumab was obtained from F. Hoffmann-La Roche Ltd. (Basel, Switzerland) as a lyophilized powder and resuspended with sterile bacteriostatic water. The suspension was further diluted with sterile water or saline for all the experiments. Cell lysates for immunoblot experiments were prepared with lysis buffer containing $1 \%$ NP-40, $50 \mathrm{mM}$ Tris ( $\mathrm{pH} 7.5$ ), $150 \mathrm{mM} \mathrm{NaCl}, 1 \mathrm{mM}$ EDTA, $1 \mathrm{mM}$ $\mathrm{Na}_{3} \mathrm{VO}_{4}$, and $1 \mathrm{mM} \mathrm{NaF}$. Proteins $(\geq 10 \mu \mathrm{g})$ were resolved by sodium dodecyl sulfate polyacrylamide gel electrophoresis (SDS-PAGE) followed by transfer to a nitrocellulose membrane. The membrane was then immunoprobed for HER2 protein (Neomarkers/Labvision, Fremont, CA, USA), phosphorylated 
extracellular regulated kinases 1/2 (pERK1/2), AKT (Cell Signaling Technology, Danvers, MA, USA) or $\beta$-actin (SigmaAldrich, St. Louis, MO, USA). Primary antibodies were diluted appropriately with 5\% non-fat milk and 3\% bovine serum albumin (BSA) in phosphate-buffered saline-Tween. The membrane was then incubated with horseradish peroxidaselinked secondary antibodies, and the proteins were detected using enhanced chemiluminescence (Amersham Biosciences, Little Chalfont, UK).

SKOV-3 HR model generation and in vivo studies. Female athymic, $n u / n u$ (nude) mice were purchased from Charles River Laboratories (Wilmington, MA, USA). Animal experiments were performed in accordance with protocols approved by the Institutional Animal Care and Use Committee and in accordance with local regulations. Mice with established, subcutaneous, palpable SKOV-3 tumors $\left(\geq 100 \mathrm{~mm}^{3}\right)$ were treated once weekly with trastuzumab administered intraperitoneally (loading dose, $4 \mathrm{mg} / \mathrm{kg}$; maintenance dose, $2 \mathrm{mg} / \mathrm{kg}$ ). Tumors that exhibited growth inhibition but later gradually progressed (so-called breakthrough tumors) were extracted, homogenized and implanted into a new set of naive, athymic $n u / n u$ mice. This procedure, which consisted of monitoring tumor growth, treating with trastuzumab and re-implanting breakthrough tumors, was repeated for four rounds. Selected breakthrough tumors were subsequently named SKOV-3 HR and cultured in vitro for further characterization. Mouse fibroblasts and other murine cells with finite replicative capacity died out during in vitro cell culture, and only viable highly proliferative human tumor cells remained. SKOV-3 HR cells were further selected by three-dimensional growth in soft agar containing exogenous trastuzumab (10-30 $\mu \mathrm{g} / \mathrm{ml})$. Afterwards, the cells were used to further characterize and profile responses to trastuzumab treatment in vitro and in vivo.

Cellular antiproliferation assay. SKOV-3 and SKOV-3 HR cells were plated at $1 \times 10^{5}$ per well in 96-well plates in complete culture medium. The following day, trastuzumab was added to the culture medium at 10 or $20 \mu \mathrm{g} / \mathrm{ml}$ with reduced $(0.5 \%) \mathrm{FBS}$. The plates were allowed to incubate for $72 \mathrm{~h}$ after the addition of trastuzumab. All treatments were performed in triplicate. ${ }^{3} \mathrm{H}$-thymidine (New England Nuclear/Perkin Elmer, Boston, MA, USA) at $0.5 \mu \mathrm{Ci} /$ well was added to all wells during the last $4 \mathrm{~h}$ before cell harvest. Cells were washed, trypsinized and harvested using a PHD glass filter scintillation harvester (Cambridge Technologies, Watertown, MA, USA). Filters containing ${ }^{3} \mathrm{H}$-thymidine-labeled cells were transferred into plastic scintillation vials and counted on a $\beta$-radiation counter (Beckman Coulter, Fullerton, CA, USA).

Fluorescence-activated cell sorting (FACS) analysis. SKOV-3, SKOV-3 HR and MDA-MB-435 cells were incubated with $10 \mu \mathrm{g} / \mathrm{ml}$ of a mouse monoclonal antibody directed against the ECD of human HER2 (Ab-2, Neomarkers/Labvision). After the cells were washed to remove unbound primary antibody, they were treated with a 1:30 dilution of a goat antimouse IgG-fluorescein isothiocyanate (FITC) secondary antibody (Chemicon International, Temecula, CA, USA). Cells were analyzed using a BD-FACStar ${ }^{\mathrm{TM}}$ instrument (Becton-Dickinson, Palo Alto, CA, USA) gating on a forward and side scatter, and the relative fluorescence was measured by excitation at $488 \mathrm{~nm}$. The percentage of cells stained with anti-HER 2 and the intensity of the staining was determined by the BD CellQuest ${ }^{\mathrm{TIN}}$ program (Becton-Dickinson) .

Scatchard plot analysis. Antibody radiolabeling with an isotopic tag has previously been described (22). Briefly, $4 \mathrm{ng}$ of ${ }^{125}$-trastuzumab $\left(4 \times 10^{5} \mathrm{CPM}\right)$ in a total volume of $100 \mu \mathrm{l}$ of Earle's balanced salt solution containing $20 \mathrm{mM}$ $\mathrm{N}-2$-hydroxyethylpiperazine- $\mathrm{N}$-2-ethanesulfonic acid, $\mathrm{pH} 7.5$, $2.5 \mathrm{mg} / \mathrm{ml} \mathrm{BSA}$ and an equal amount of unlabeled trastuzumab were incubated at $20^{\circ} \mathrm{C}$ for $2 \mathrm{~h}$ with SKOV-3 and SKOV-3 HR cells grown in $1-\mathrm{cm}^{2} 48$-well plates. At the end of the incubation period, the unbound radioactivity was removed by washing cell monolayers three times with ice-cold binding buffer. The cells were solubilized by adding $0.5 \mathrm{ml}$ of $1 \mathrm{M} \mathrm{NaOH}$ and heated at $65^{\circ} \mathrm{C}$ for $30 \mathrm{~min}$. Non-specific binding, which was 3-5\% of the total binding, was determined by incubating the cells with labeled antibody in the presence of 100 -fold excess unlabeled antibody. The non-specific binding was subtracted from the total binding to determine the specific binding.

HER2 DNA sequencing and reverse transcriptase-polymerase chain reaction. Primary DNA sequencing and reverse transcriptase polymerase chain reaction (RT-PCR) have previously been described (23). Briefly, poly (A) ${ }^{+}$RNA was directly isolated and converted to single-strand CDNA as a template for PCR amplification from cells growing in culture. A total of six PCR reactions designed to generate sufficient overlapping HER2 DNA fragments were performed for each cell line. PCR was run for 40 cycles using high fidelity $p f x$ DNA polymerase. A fraction of the PCR-amplified products was resolved on a $1 \%$ agarose gel and stained with ethidium bromide. The remaining PCR products were gel-purified for DNA sequencing. Six PCR amplicons were used to cover the entire HER2 coding region.

MEP and genomic analysis. MEP using Affymetrix gene chips (Santa Clara, CA, USA) has previously been described (24). SKOV-3 and SKOV-3 HR cells were incubated with or without trastuzumab $(50 \mu \mathrm{g} / \mathrm{ml})$ for $72 \mathrm{~h}$. Cells were harvested, total RNA was isolated and purified, cDNA was generated and mRNA was scanned onto Affymetrix gene chips. In vitro transcription and hybridization were performed with human genome U133 set consisting of two GeneChip arrays (Affymetrix) with 45,000 probe sets. These probe sets represent more than 39,000 transcripts derived from approximately 33,000 well-substantiated human genes. After uploading the results to the Affymetrix laboratory information management system, signal intensities were retrieved from the database for analysis. Normalization was performed by sample via median scaling to the median of all chips in the study. Normalization was not performed on the gene level.Differentially expressed genes with greater than a two-fold $(\mathrm{p} \leq 0.05)$ difference in fluorescence expression were filtered and isolated from background. T-tests were performed for two sets of comparisons. First, the treated population was compared with the control population in the parental background to determine the effects of trastuzumab treatment. Probe sets were selected that reached a p-value cut-off of $<0.05$ and at least a two-fold change in either the positive or negative direction. Probe sets with a maximum expression in either of the two conditions of 
A

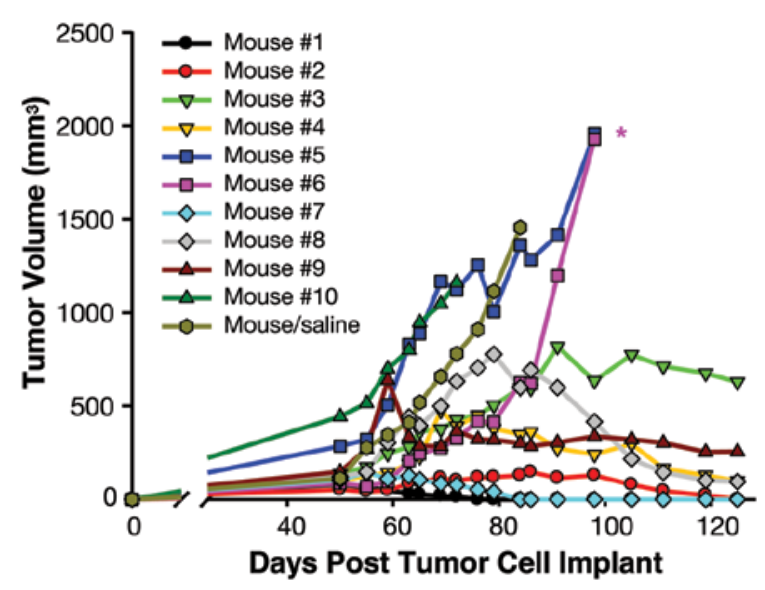

C

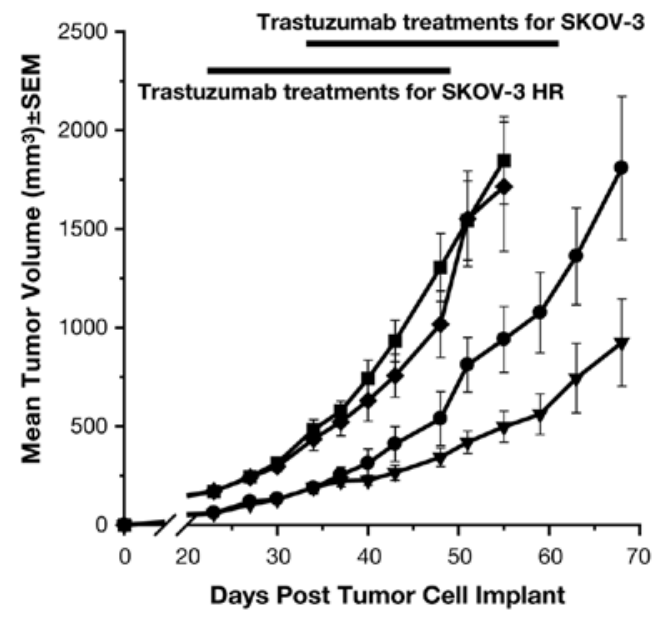

$<25$ were omitted for low expression. The second comparison was between the acquisition of probe sets from parental and resistant background samples. The list of genes that were identified was annotated using the Affymetrix NetAff ${ }^{\mathrm{TM}}$ system at the probe set level. Biological functions were assigned to each gene network using the Ingenuity Pathways Knowledge Base (Mountain View, CA, USA). The Ingenuity Pathways program cross-references the entered probe sets from the NetAffx system and assigns a network of genes with biological links or interactions based on data obtained from published literature (25). Fisher's exact test is used to calculate a p-value that determines the probability that the biological function assigned to that network can be explained by chance alone.

MUC1 expression by immunohistochemistry. SKOV-3 and SKOV-3 HR cells and tumors were fixed in $10 \%$ neutral buffered formalin. The expression of glycosylated MUC1 on the cell surface was determined by incubating the cells with the NeoMarkers MUC1 peroxidase-conjugated antibody (cat. no. RB-9222-P; Fremont, CA, USA) or the human MUC1 Ab-5 alkaline phosphatase-conjugated antibody, which recognizes amino acids 239-255 on the MUC1 cytoplasmic domain. Antigen unmasking was performed on the samples prior to the
B

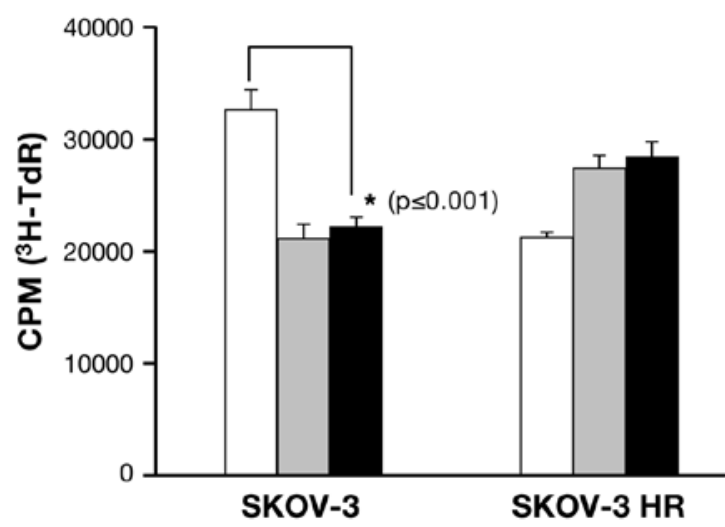

Figure 1. (A) SKOV-3 cells $\left(5 \times 10^{6}\right.$ cells/mouse) were implanted subcutaneously in the right hind flank of ten female athymic $n u / n u$ mice with BD Matrige ${ }^{\mathrm{TM}}$. For each mouse, treatments started when tumor volume reached $>100 \mathrm{~mm}^{3}$. Trastuzumab ( $4 \mathrm{mg} / \mathrm{kg}$ loading dose for one week and $2 \mathrm{mg} / \mathrm{kg}$ thereafter) was administered intraperitoneally weekly for the entire duration of the study (>120 days post-implantation). "Mouse number 6 showed initial inhibition of tumor growth but later lost this response. The tumor from this mouse was passaged into ten naive $n u / n u$ mice in the second round for further selection. (B) SKOV-3 and SKOV-3 HR cells $\left(5 \times 10^{4} /\right.$ well) were seeded in triplicate in 96-well plates, and the next day trastuzumab was added at the indicated doses (white bars, culture medium; gray bars, $10 \mu \mathrm{g} / \mathrm{ml}$ trastuzumab; black bars, $20 \mu \mathrm{g} / \mathrm{ml}$ trastuzumab). Plates were allowed to incubate at $37^{\circ} \mathrm{C}, 5 \% \mathrm{CO}_{2}$ for an additional $2 \mathrm{~h} .{ }^{3} \mathrm{H}$-thymidine was added $18 \mathrm{~h}$ prior to harvest. $\beta$-radiation emission counts per well were averaged and graphed as radiation counts per min. (C) SKOV-3 and SKOV-3 HR cells ( $5 \times 10^{6}$ cells/mouse) were implanted subcutaneously in the right hind flank of female athymic nu/nu mice with Matrigel $(1: 1 \mathrm{v} / \mathrm{v})$. Treatments started at the indicated time when group mean tumor volume reached approximately $100-200 \mathrm{~mm}^{3}$. Trastuzumab $(4 \mathrm{mg} / \mathrm{kg}$ loading dose for one week and $2 \mathrm{mg} / \mathrm{kg}$ thereafter) and vehicle were administered intraperitoneally weekly for 4.5 weeks. Circle, SKOV-3 cells treated with vehicle (sterile saline); triangle, SKOV-3 cells treated with trastuzumab; square, SKOV-3 HR cells treated with vehicle; diamond, SKOV-3 HR cells treated with trastuzumab. CPM, counts per min; HR, Herceptin-resistant; SEM, standard error of mean.

addition of the primary antibodies. Samples were incubated with the primary antibody for approximately $18-24 \mathrm{~h}$ at $4^{\circ} \mathrm{C}$. After repeated washing ( $\geq 3$ times) in wash buffer, samples were incubated with secondary antibodies for $30 \mathrm{~min}$ at room temperature. Staining was performed with fast red chromogen until the fixed cells turned dark red-brown in color. After washing in distilled water and dehydrating in ethanol, coverslips were mounted on the slides. Photographs of slides were taken with a light microscope using $\mathrm{x} 40$ magnification.

\section{Results}

Selection of SKOV-3 HR tumors and lack of antiproliferative and antitumor response to trastuzumab. The development of the SKOV-3 HR model involved the induction of acquired resistance over time in the in vivo setting through continuous exposure to trastuzumab. Initially, trastuzumab-sensitive SKOV-3 cells were implanted subcutaneously in athymic $n u / n u$ mice, which were administered a therapeutic dose of trastuzumab once a week when tumors were firmly established (26). Tumor growth from individual animals was monitored for more than 120 days post implant. When tumor progression occurred, breakthrough tumors that reached $\geq 1000 \mathrm{~mm}^{3}$ were extracted, 
A
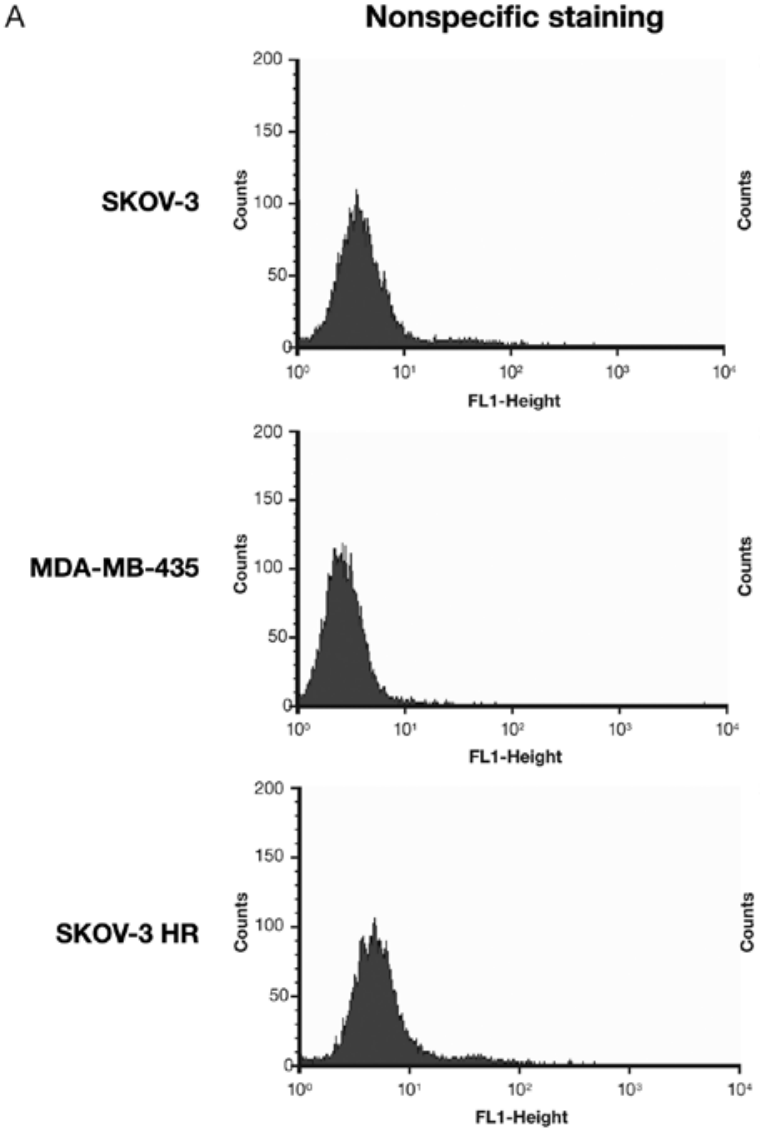

HER2-specific staining
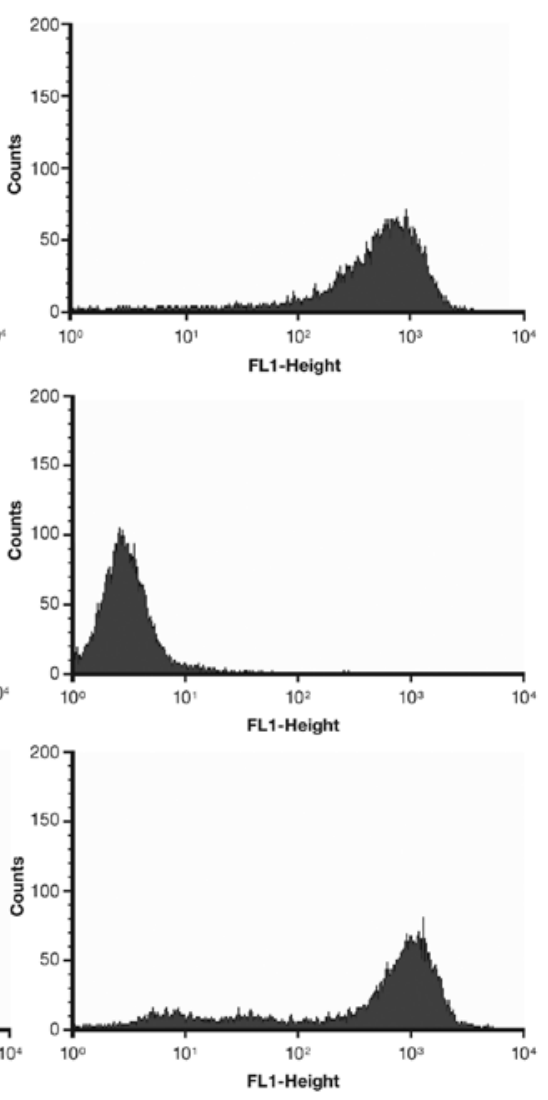

B

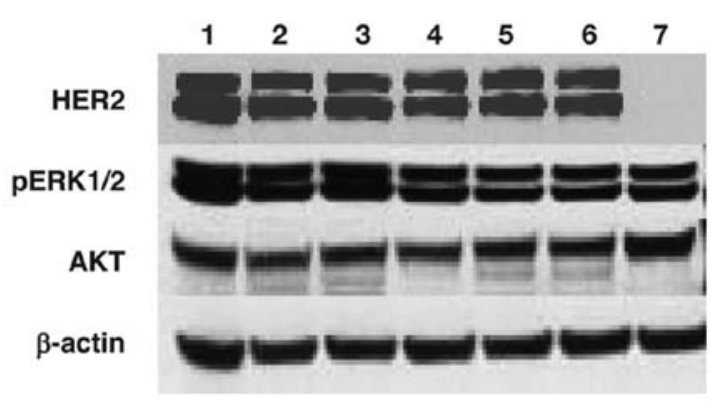

Figure 2. (A) Determination of HER2 cell surface receptor expression was performed by FACS analysis. SKOV-3, MDA-MB-435 and SKOV-3 HR cells were tested for HER 2 receptors with mouse monoclonal antibody against ECD followed by a secondary goat antimouse FITC-antibody. Non-specific staining refers to fluorescence uptake with the secondary antibody only, while specific staining indicates fluorescence uptake with primary and secondary antibodies. The mean channel fluorescence was similar in testing all cell lines, indicating similar levels of cell surface HER2 receptors on SKOV-3 and SKOV-3 HR cells. (B) Immunoblot of SKOV-3, SKOV-3 HR and Hek293 (HER2-negative control). Multiple samples of SKOV-3 (lanes 1-3) and SKOV-3 HR (lanes 4-6), and one sample of Hek293 (lane 7) cell lysates were blotted for protein expression levels of HER2, AKT, and p44/42 (mitogen-activated protein kinase). $\beta$-actin served as the loading control. FACS, fluorescence-activated cell sorting; ECD, extracellular domain; FITC, fluorescein isothiocyanate; HER2, human epidermal growth factor receptor; HR, Herceptin-resistant; pERK1/2, phosphorylated extracellular regulated kinases $1 / 2$. processed, divided equally and implanted into a new set of naive mice (Fig. 1A). In the second round, upon tumor establishment, trastuzumab treatment was again initiated and tumor responses were followed. Three or four rounds of in vivo serial passaging of breakthrough tumors were carried out to ensure there was a lack of, or negligible, response to trastuzumab before these tumors were cultured in vitro and characterized.

First, the effects of exogenously added trastuzumab on the proliferation of the breakthrough SKOV-3 HR cells were determined in vitro. Trastuzumab was added to plates of cultured SKOV-3 and SKOV-3 HR cells, and the incorporation of ${ }^{3} \mathrm{H}$-thymidine was measured as an indicator of proliferation. $\beta$-radiation emissions revealed that the addition of trastuzumab inhibited SKOV-3 proliferation compared with cells incubated in culture medium alone (Fig. 1B). Even a low dose of trastuzumab $(10 \mu \mathrm{g} / \mathrm{ml})$ over $72 \mathrm{~h}$ of incubation was enough to notice a difference in proliferation compared with the control. Interestingly, trastuzumab did not have an antiproliferative effect on the SKOV-3 HR cells (Fig. 1B). These proliferation experiments were performed at least twice and similar outcomes were obtained each time.

To confirm the resistance of SKOV-3 HR cells to trastuzumab, the effect of treatment with trastuzumab on these cells was again examined in vivo. In a xenograft efficacy experiment, the effects of trastuzumab therapy were compared side by side in athymic nu/nu mice that were implanted with SKOV-3 and SKOV-3 HR tumors. SKOV-3 HR tumors became palpable more rapidly and grew faster than parental SKOV-3 tumors (Fig. 1C). Trastuzumab treatment for mice implanted with SKOV-3 tumors was delayed for 11 days to ensure that the starting tumor volumes (approximately 100-200 $\mathrm{mm}^{3}$ ) were similar to SKOV-3 HR tumor volumes. Trastuzumab inhibited SKOV-3 


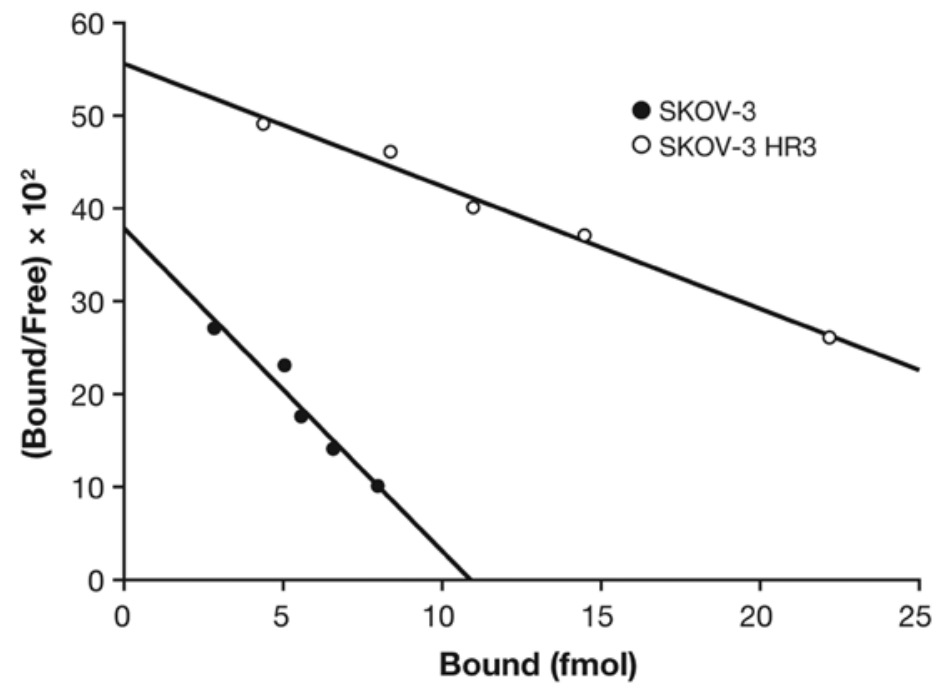

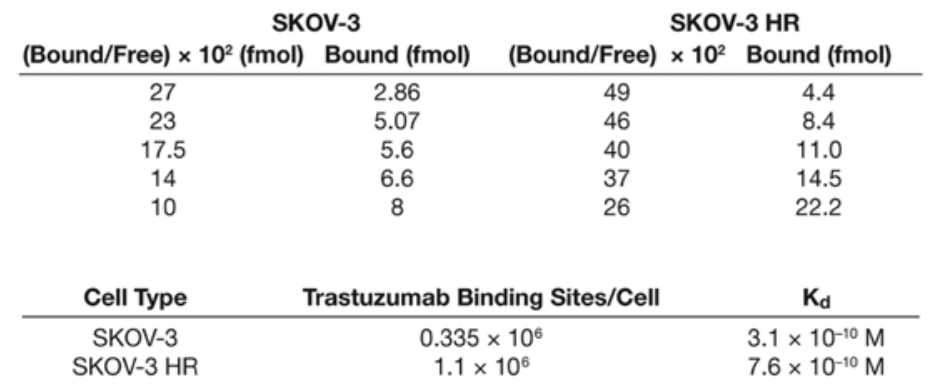

Figure 3. Scatchard plot analysis of SKOV-3 (black circles) and SKOV-3 HR (white circles) cells were performed to evaluate trastuzumab binding sites and binding affinity $\left(\mathrm{K}_{\mathrm{d}}\right)$. Cells were grown in 48 -well plates and incubated with increasing concentrations of ${ }^{125}$ I-trastuzumab. Non-specific binding was determined by adding unlabeled trastuzumab (100-fold excess). The non-specific binding was subtracted from the total binding to determine specific binding. The line of best fit was determined by linear regression. The number of cells per well used for the binding assay were SKOV-3, 19x10 3 ; SKOV-3 HR, 23x10 .

tumor growth by $50 \%(\mathrm{p}=0.05)$ compared with SKOV-3 vehicletreated controls over a 4.5 -week treatment period. SKOV-3 HR tumor growth, in contrast, was not inhibited by trastuzumab that was given at the same treatment regimen and schedule (tumor growth inhibition $=8 \%, \mathrm{p}=0.734$ ).

HER 2 receptor expression and downstream signaling. The lack of trastuzumab activity in vitro and in vivo against SKOV-3 HR cells may be due to the loss of cell surface HER2 receptor expression. To address this possibility, levels of cell surface HER2 expression on SKOV-3 and SKOV-3 HR cells were compared. The MDA-MB-435 cell line, a human breast carcinoma cell line that has low HER2 protein expression, served as the negative control. SKOV-3, SKOV-3 HR and MDA-MB-435 cells were incubated with labeled FITC-conjugated mouse monoclonal antibody against the human HER2 receptor ECD. FACS analysis revealed that SKOV-3 and SKOV-3 HR cells had similar levels of expression of cell surface HER2 receptors (Fig. 2A), suggesting that these SKOV-3 HR cells may exhibit aberrant signaling downstream from HER2.

Downstream signaling components were then evaluated for alterations in their protein expression. Immunoblotting was used to determine the total protein levels of p44/42 (pErk1/2) and AKT in cell lysates from SKOV-3, SKOV-3 HR and Hek293 cells (Fig. 2B), with Hek293 serving as the HER2-negative control. The results revealed no significant differences in the expression levels of AKT and pERK1/2 (p44/42) between SKOV-3 and SKOV-3 HR cells.

Increased binding sites but decreased binding affinity. A ligand receptor-binding assay and Scatchard plot analysis were performed with radioactively tagged trastuzumab to determine the binding affinity of trastuzumab for cognate HER2 receptors. Purified ${ }^{125}$ I-labeled trastuzumab was exogenously added to SKOV-3 and SKOV-3 HR cells in culture and later saturated with unlabeled or cold trastuzumab for competitive binding. Scatchard plot analysis revealed that ${ }^{125}$ I-trastuzumab bound to more binding sites on the surface of SKOV-3 HR cells $\left(1.1 \times 10^{6}\right.$ sites/cell $)$ than of SKOV-3 cells $\left(0.335 \times 10^{6}\right.$ sites/cell). However, the binding affinity was decreased by approximately two- to three-fold (7.6x10 $10^{-10}$ vs. $3.1 \times 10^{-10} \mathrm{M}$, respectively; Fig. 3).

Sequencing of HER2 primary DNA transcripts. As the number of trastuzumab binding sites is increased on SKOV-3 HR cells, the decreased binding affinity of trastuzumab for these cells could be due to an alteration or mutation in the HER2 ECD. To address this, the HER2 primary transcripts from both cell lines were compared. Six PCR amplicons with overlapping sizes were used to cover the entire HER2 coding region (Fig. 4A). All PCR products were found at the expected sizes by agarose gel electrophoresis (Fig. 4B). Overall, the PCR amplified products from both cell lines were identical. Analyzing the DNA 
A

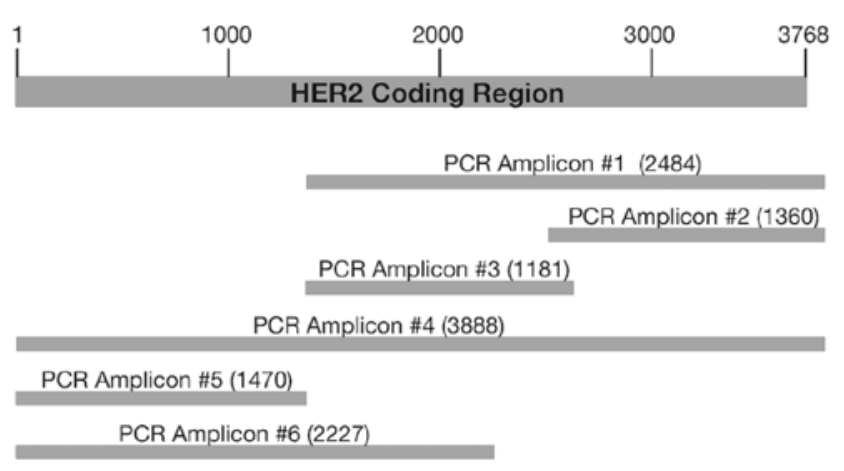

B

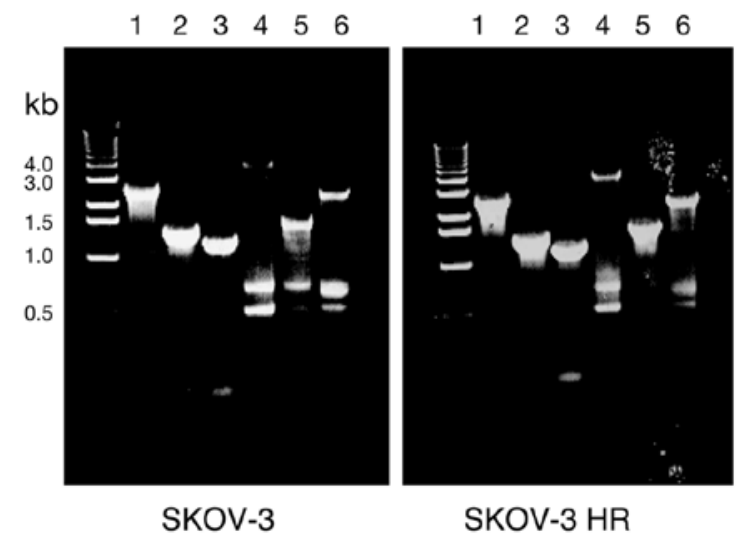

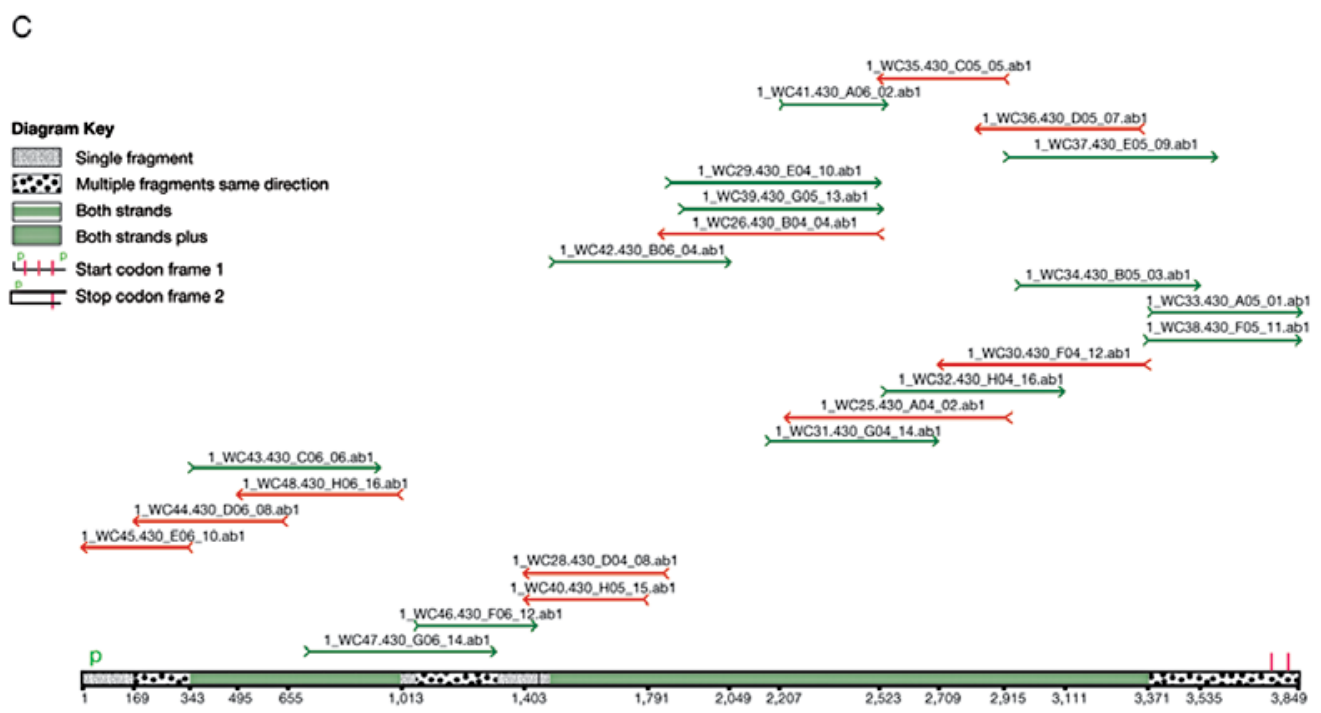

Figure 4. (A) DNA sequencing strategy for HER2-negative cells; green lines designate location and length of each PCR amplified HER2 DNA fragment. DNA fragment length in base pairs are indicated in parentheses. (B) PCR amplification of HER2 DNA sequences. The lane numbering corresponds to the PCR amplicon number. All DNA fragments were found to be at the expected size, and all were purified and used for DNA sequencing (except for no. 4 due to low yield). (C) Compilation of all sequencing reactions for HER2 overlapping DNA fragments from SKOV-3 HR cells. Each arrow represents the sequence length and direction of a DNA sequence reaction. The consensus sequence is indicated as rectangle at bottom. The same sequencing strategy was applied to SKOV-3 cells. HER2, human epidermal growth factor receptor 2; PCR, polymerase chain reaction.

sequence following RT-PCR revealed that the full-length HER2 sequences obtained from SKOV-3 and SKOV-3 HR cells were identical (Fig. 4C). Both sequences aligned well with a HER2 sequence from a published database (e.g., SWISSPROT). Therefore, the decreased binding affinity of trastuzumab for HER2 receptors on the SKOV-3 HR cells is likely not due to mutations in the $H E R 2$ gene.

Genes differentially expressed in SKOV-3 HR cells. Through in vivo induction of acquired resistance with continuous trastuzumab treatment of tumor-bearing mice, the SKOV-3 HR cells underwent specific genomic changes that differentiated them from their parental counterparts. Performing MEP using Affymetrix gene chips revealed genes that may have given rise to the resistance phenotype or, as a result of the resistance induction, were now distinctly expressed genes. Genes with expression that differed by a greater than two-fold $(\mathrm{p} \leq 0.05)$ magnitude of difference in fluorescence were filtered and isolated from background. Fluorescence expression analysis revealed that a larger number of genes were affected by trastuzumab in the parental background than in the resistant background, suggesting that trastuzumab induced or affected the functionality of the SKOV-3 cells. The gene chip fluorescence results were annotated using the Affymetrix NetAffx system at the probe set level. Biological functions were assigned to each gene network using the Ingenuity Pathways Knowledge Base. The Ingenuity Pathways program identified a set of genes with a known biological link or interaction with the EGFR family. The basal fluorescence expression of these genes in the two cell lines is presented in Fig. 5A. The expression of these genes in the two cell lines after trastuzumab treatment is shown in Fig. 5B. This set of 33 genes was differentially expressed between the two cell lines and had a greater than two-fold change in expression level between the basal state and after trastuzumab treatment. The genes that the Ingenuity Pathways program assigned biological functions to have notable and well-studied roles in tumorigenesis, angiogenesis, invasion and metastases, apoptosis, proliferation and survival. Some of these genes include angiopoietin 2, nestin, 
A

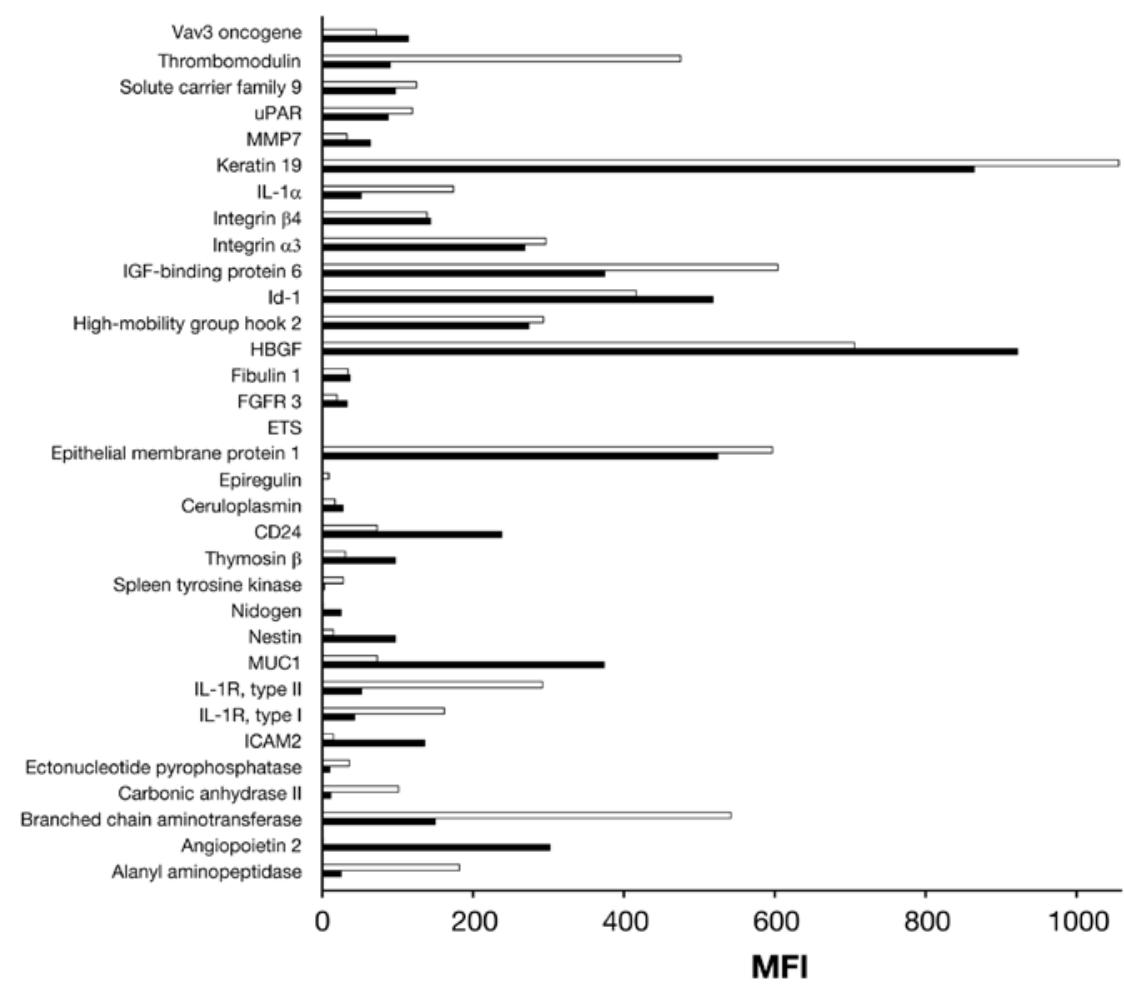

B

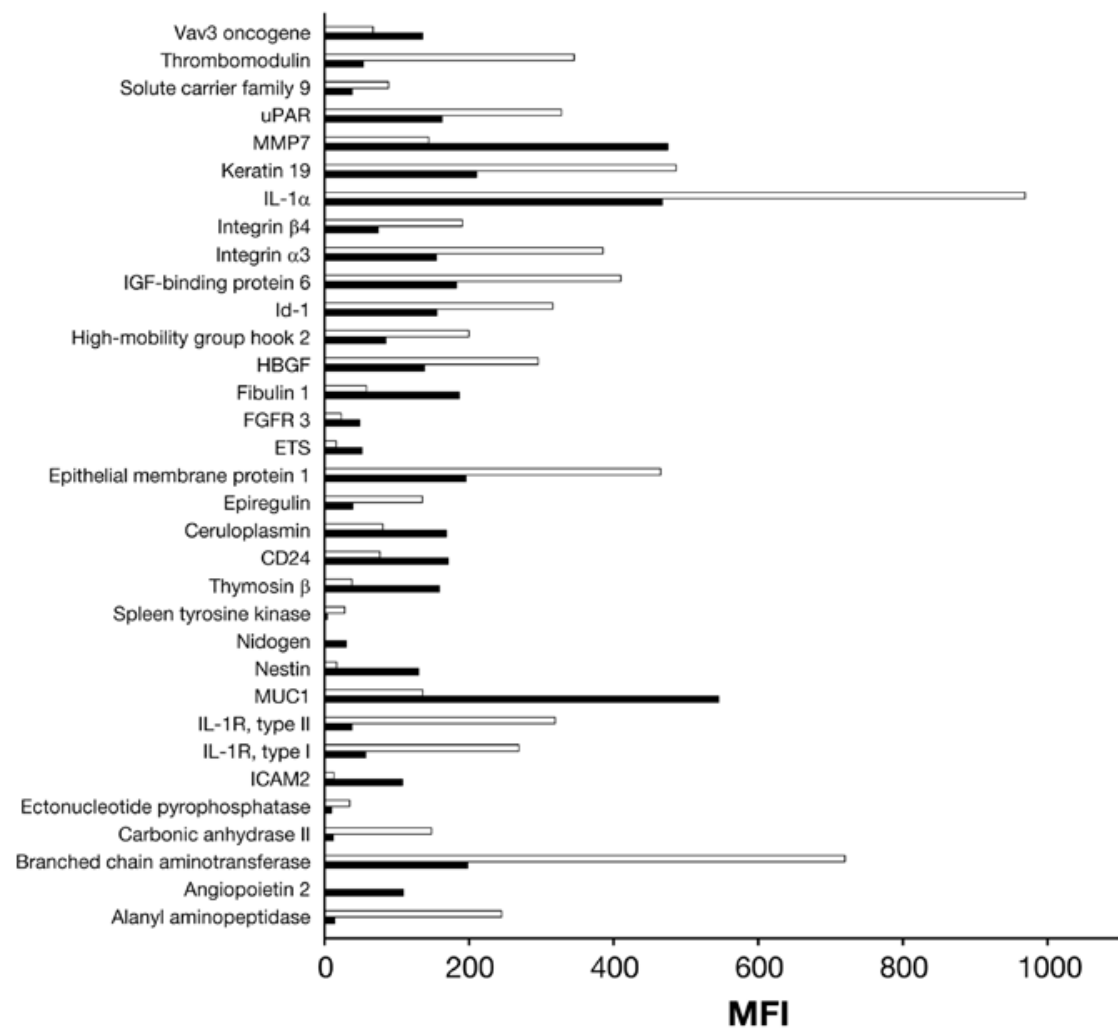

Figure 5. MFI of genes that were identified with differential expression by the Ingenuity Pathways program under (A) basal or constitutive condition (without trastuzumab treatment), and (B) with the addition of trastuzumab $(50 \mu \mathrm{g} / \mathrm{ml})$ for $72 \mathrm{~h}$ after signal intensities were retrieved from the Affymetrix LIMS database and normalized using median scaling to the median of all chips. Probesets were selected which reached a p-value cut-off of $<0.05$ and a fold change of at least two-fold in either the positive or negative direction. SKOV-3 cells, white bars; SKOV-3 HR cells, black bars. ETS, E-twenty-six; FGFR, fibroblast growth factor receptor; ICAM2, intercellular adhesion molecule 2; IGF, insulin-like growth factor; IL-1, interleukin 1; HBGF, heparin-binding growth factors; MFI, mean fluorescence intensity; MMP7, matrix metalloproteinase-7; MUC1, mucin 1; uPAR, urokinase plasminogen activator receptor. 
A

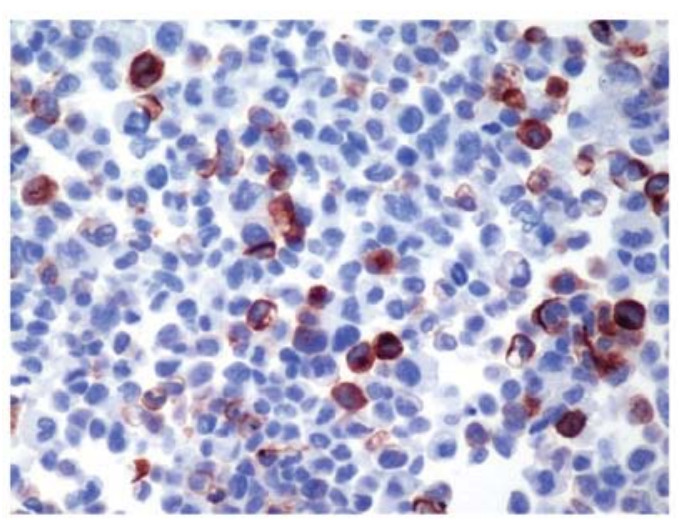

C

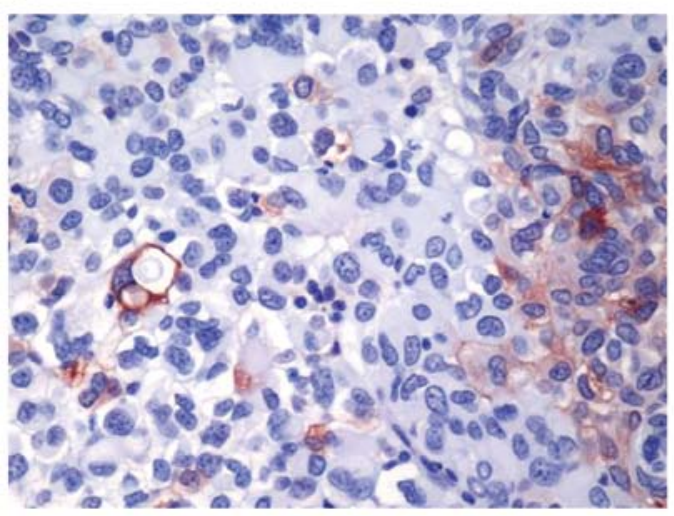

B

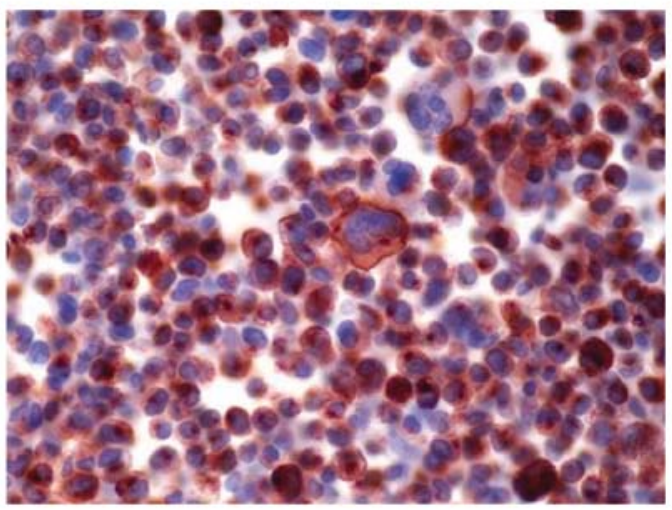

D

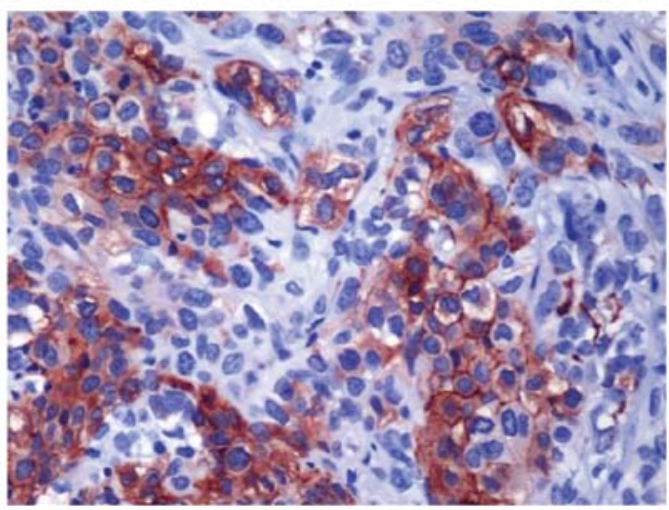

Figure 6. (A) Image of SKOV-3 cells stained with antibody against MUC1 (dark red-brown cells). (B) MUC1 is overexpressed in SKOV-3 HR cells. Slides viewed under X40 magnification. (C and D) Extracted SKOV-3 and SKOV-3 HR subcutaneous tumors, respectively, fixed and IHC stained for human MUC1. Photographs taken under at x40 magnification. HR, Heceptin-resistant; MUC1, mucin 1.

ceruloplasmin, fibroblast growth factor receptor 3 , integrin $\alpha / \beta$, Vav3 oncogene, matrix metalloproteinase-7, keratin 19, CD24, ETS transcription factor, intercellular adhesion molecule 2, urokinase plasminogen activator receptor, epiregulin, thrombomodulin, Id-1, heparin-binding growth factor, IGF-binding protein 6 and $M U C 1$.

MUC1 is overexpressed in SKOV-3 HR cells. The role of MUC1 in cancer pathogenesis has been extensively studied, and MUC1 is known to interact with the EGFR family (27). Since the MUCl gene was shown to be highly expressed in SKOV-3 HR cells, MUC1 protein expression was confirmed by IHC. Examination of the MUC1 cell surface and cytoplasmic expression revealed a striking difference in MUC1 positivity between SKOV-3 and SKOV-3 HR cells. Not only was MUC1 expression on the cell surface of the SKOV-3 cells dramatically decreased compared with the SKOV-3 HR cells, there were significantly fewer SKOV-3 cells that were positive for MUC1 (Fig. 6A and B). Almost all ( $\geq 90 \%)$ of the SKOV-3 HR cells were stained dark red-brown for positive MUC1 expression compared with $\leq 20 \%$ of the SKOV-3 cells. Moreover, the intensity of positive MUC1 staining on SKOV-3 HR cells was greater compared with that of the parental cells. The overexpression of MUC1 protein on SKOV-3 HR cells correlated with the significantly higher gene expression obtained from the microarrays. Examination of SKOV-3 and SKOV-3 HR in vivo subcutaneous tumors for MUC1 expression revealed a pattern similar to that observed with the cultured cells. MUC1 expression by IHC in the SKOV-3 HR cells was more intense than the MUC1 expression on parental SKOV-3 tumors that were extracted at the same time (Fig. 6C and D).

\section{Discussion}

The development and subsequent approval of trastuzumab has led to the availability of the first antibody-based molecular targeted therapy for MBC in patients whose tumors have HER2 gene amplification and concomitant HER2 protein overexpression. However, despite clinical responses observed with both monotherapy and in combination regimens, there are still many patients whose tumors progress on trastuzumabbased therapy, indicating acquired resistance to therapy (28). Moreover, a subset of patients do not have objective responses despite HER 2 overexpression, indicating that they may have some form of de novo or intrinsic resistance. Thus, patients with HER2-positive breast cancer who do not respond to trastuzumab or progress during trastuzumab-based treatment may benefit from new therapeutics with different targets, or different treatment regimens. Studies exploring the mechanism of trastuzumab resistance in preclinical cancer models as well 
as methods to reverse resistance, thereby restoring sensitivity to and effectiveness of trastuzumab treatment, are ongoing (16-21,29-31). Preclinical studies, including our own, have demonstrated the antitumor activity of trastuzumab in experiments using ovarian carcinoma models with intrinsic HER2 overexpression. However, not all HER2-overexpressing tumors respond to trastuzumab, the reasons for which are unclear, and there is a continuous need to investigate the mechanisms behind the lack of translational efficacy. The knowledge we gain from studying models with sensitivity to trastuzumab and investigating the subsequent loss of that sensitivity is vital for future management of the disease and the improvement of treatment options. Intrinsic and acquired resistance, as well as genetic or epigenetic factors, may limit the effectiveness of trastuzumab in ovarian cancers and other HER2-overexpressing epithelial cancers $(6,32)$.

Our group is the first to develop a preclinical model of ovarian carcinoma, SKOV-3 HR, with induced (or acquired) resistance to trastuzumab. The SKOV-3 HR model was developed from the parental SKOV-3 cell line. SKOV-3 is used by many investigators to demonstrate the in vitro and in vivo antiproliferative and antitumor effects of trastuzumab, making it a useful tool to investigate resistance mechanisms from a preclinical perspective $(3,33)$. We generated the SKOV-3 HR model by in vivo serial passaging of SKOV-3 tumors that had lost sensitivity to trastuzumab for three to four rounds. SKOV-3 HR is the first trastuzumab-resistant ovarian model to be developed by this method, which, as an in vivo model, may prove to be more clinically relevant than an artificial in vitro tissue culture environment.

The results from our study with the SKOV-3 HR model may be cross-referenced or translatable to other preclinical models or clinical specimens, aiding in deciphering the mechanisms of trastuzumab resistance and ultimately in developing strategies and therapies to overcome such mechanisms. For instance, several laboratories have developed trastuzumab-resistant breast cancer cell lines that are sensitive to EGFR tyrosine kinase inhibitors (34). Similarly, we observed that the SKOV-3 HR tumors developed in this study also exhibit sensitivity to the tyrosine kinase inhibitor erlotinib (data not shown). In addition, evidence has emerged that trastuzumab resistance can be circumvented or abrogated by targeting HER2 receptor heterodimerization and kinase activity, or disruption of HER2 signaling with another anti-HER2 antibody, such as pertuzumab $(35,36)$.

The characterization of SKOV-3 HR cells revealed constitutive expression of the HER2 protein similar to that observed with trastuzumab-sensitive parental cells. Similar findings of unaltered HER2 expression and downstream growth signaling regulators before and after trastuzumab treatment have been observed in other models of trastuzumab resistance, implying that cancer cells can circumvent trastuzumab activity but continue to depend on the activation of the HER2 oncogene $(19,34)$. HER2 overexpression and protein downregulation that result from trastuzumab treatment are not predictors of response (37). Therefore, factors other than HER2 overexpression may be predictive of antitumor response to trastuzumab in ovarian cancer (38). However, the fundamental reasons for the clinical activity of trastuzumab in HER2-positive breast and gastric cancers, but not in other HER2-positive cancers, such as ovarian cancer, are not completely understood.
We demonstrate that trastuzumab is not effective against SKOV-3 HR proliferation and in vivo tumor growth. The reasons for these findings could be due to the ineffectual/incomplete binding of trastuzumab to HER2 receptors, as demonstrated by the receptor/ligand binding assay and Scatchard plot analysis. We found that there was a three-fold or greater increase in trastuzumab binding sites on SKOV-3 HR cells, but which was accompanied by a decrease in binding affinity compared with the parental line. This decreased trastuzumab binding affinity could indicate an alteration in the trastuzumab recognition or binding epitope on the HER2 ECD; however, DNA sequence analysis revealed that the HER2 primary transcripts from both cell lines were similar, with no obvious differences. Similar results regarding the increase in binding sites and the diminished binding affinity were noted in the characterization of JIMT-1, a trastuzumab-resistant breast cancer cell line, by Nagy et al (19). Moreover, the JIMT-1 cells retained HER2 amplification and protein overexpression and maintained unaltered expression of downstream growth regulatory signaling proteins, which was also observed with the SKOV-3 HR cells in this study.

Determination of the genomic differences between SKOV-3 and SKOV-3 HR may aid in elucidating the mechanisms of the development of resistance. MEP identified a set of genes that were differentially expressed at constitutive or basal levels between parental SKOV-3 and SKOV-HR cells. A similar MEP was performed after the addition of in vitro exogenous trastuzumab to cells in culture. The Ingenuity Pathways program identified a dataset of 33 genes that have direct network/links/interactions to HER/EGFR biological processes. Functional analysis grouped these genes by their role in biological processes, such as angiogenesis/invasion, differentiation, proliferation, cell growth and survival. These genes included $M U C 1$, angiopoietin 2, CD24, Vav3 oncogene, nestin and ETS transcription factor, whose differential and dysregulated expression and subsequent biological interaction with the EGFR family could support the development of SKOV-3 HR cells that are phenotypically aggressive with acquired therapeutic resistance to trastuzumab.

One of the genes that was overexpressed at least five-fold at the genomic and protein level by the SKOV-3 HR cells compared with the SKOV-3 cells is MUC1. MUC1 is an $\mathrm{O}$-glycosylated transmembrane protein that is aberrantly expressed in a majority of breast, ovarian and many other epithelial carcinomas (39). Cell surface mucins interact with the EGFR family to regulate signaling events related to cell growth, motility, differentiation, inflammation and other higherorder functions. MUC1 protein overexpression in SKOV-3 HR cells was confirmed by the marked positive staining by IHC. SKOV-3 HR tumors exhibit distinct MUC1 overexpression, which may contribute to a more robust tumorigenicity and the overt aggressive growth of the tumor cells. MUC1 expression is highly regulated and can be inhibited by HER2 overexpression in transformed mammary epithelial cells (40). Conceivably, the long-term use of trastuzumab could have led to HER2 inhibition, and, possibly in conjunction with the altered expression of the genes that we identified (angiopoeitin 2, increased nestin, increased Vav3 oncogene expression) caused the upregulation of MUC1 mRNA and protein overexpression in SKOV-3 HR tumors. Consequently, this course of events could have led to the formation of an aggressive phenotype that confers resistance to trastuzumab. 
Cell surface mucins such as MUC1 form complex multivalent tandem oligosaccharide repeats that form densely arrayed, highly ordered structural layers that facilitate the ingress and egress of molecules to the cell. These oligosaccharide tandem repeats surround the tumor cell like a molecular 'shield' to block toxic compounds, such as chemotherapeutic agents or anticancer antibodies (41). Therefore, similar to MUC4 in the JIMT-1 cells, overexpression of MUC1 in SKOV-3 HR cells could present a steric barrier or constraint that affects the binding of trastuzumab to HER2 receptors, thereby causing a decrease in binding affinity and a subsequent lack of antiproliferative response. Furthermore, the increased phosphorylation of MUC1 could potentiate downstream signaling pathways, such as Ras/Raf/Erk (MAPK), leading to uncontrolled growth and survival (27).

The data obtained from these studies provide further evidence of the role of MUC1 in trastuzumab resistance. For instance, Fessler et al showed that a cleaved form of the MUC1 protein $\left(\mathrm{MUCl}^{*}\right)$ is upregulated in trastuzumab-resistant breast cancer cells and that the inhibition of $\mathrm{MUCl}^{*}$ could reverse resistance and restore trastuzumab sensitivity (30). Moreover, the expression of $\mathrm{MUCl}^{*}$ could be involved in so-called intrinsically resistant or refractory HER2-positive cancers (IHC 1 ${ }^{+} / 2^{+} \mathrm{HER} 2$ positive breast cancer and ovarian cancer) for which trastuzumab is less effective. Therefore, the combination of trastuzumab and a MUC1 antagonist could be used to reverse acquired and intrinsic resistance to trastuzumab, and may be effective in deterring the onset of resistance in the adjuvant setting.

Zhang et al showed that increased c-SRC activation mediated by the loss of PTEN or the overexpression of EGFR or the type 1 IGF receptor (IGF1R) can confer therapeutic resistance to trastuzumab in breast cancer cells, and the direct dephosphorylation of c-SRC can restore trastuzumab sensitivity (21). Of note, MUC1 is associated with the c-SRC tyrosine kinase. c-SRC phosphorylates the MUC1 cytoplasmic domain and can inhibit the interaction between MUC1 and glycogen synthase kinase 3- $\beta$. Moreover, the c-SRC-mediated phosphorylation of MUC1 can increase the binding of MUC1 and $\beta$-catenin (42). Thus, the overexpression of MUC1 in the SKOV-3 HR cells and the interaction with its substrate, c-SRC, may implicitly confer resistance to trastuzumab.

Other mechanisms of resistance to trastuzumab that were proposed from research in preclinical models include amplification of HER/ErbB signaling, cross-talk with heterologous receptor tyrosine kinases, accumulation of the constitutively active truncated p95-HER2, alternate or amplification of survival signaling pathways, such as the IGF1R and PI3K/AKT pathways, respectively, and the alteration of downstream signaling, such as the loss of PTEN. This diversity suggests that no one mechanism may be responsible for causing the resistance of HER2-overexpressing tumor cell to trastuzumab. Our data add to the knowledge that continues to accumulate in this field, and strategies are being developed to overcome resistance in trastuzumab-treated patients. For instance, novel agents are being evaluated as single agents or in combination, in patients with HER2-positive MBC that has progressed on prior trastuzumab therapy. For example, pertuzumab in combination with trastuzumab has demonstrated a response rate of $24.2 \%$ in patients in this setting (43). Trastuzumab emtansine (T-DM1), composed of trastuzumab conjugated via a stable thioether linker to DM1 (a potent microtubule inhibitor), has also demonstrated activity in this setting. Phase II trials evaluating single-agent T-DM1 have demonstrated response rates of 35.5 and $25.9 \%$ in patients with HER2-positive MBC who had received prior trastuzumab and chemotherapy $(44,45)$. Lastly, lapatinib, a small molecule HER2 and EGFR kinase inhibitor, has a mechanism of action distinct from trastuzumab (46). Clinical benefit in the trastuzumab-refractory HER2-positive MBC setting was observed when lapatinib was administered in combination with chemotherapy, resulting in a reduction in the risk of progression of $51 \%$ in the lapatinib arm compared with the control arm (47).

Our study on the development and characterization of the SKOV-3 HR trastuzumab-resistant ovarian carcinoma model add to the increasing body of knowledge of resistance mechanisms observed with many cancer therapies. Our proposed mechanism of trastuzumab resistance supports therapies that target MUC1 along with HER2 to achieve increased antitumor efficacy. Moreover, we identified a gene signature that may be responsible for the onset of resistance to trastuzumab and could provide the basis for elucidating the lack of trastuzumab activity in patients with ovarian cancer. This gene signature could correlate with clinical samples with acquired and intrinsic resistance and could potentially provide the basis for identifying patient populations that may or may not respond to trastuzumab treatment. Although further research is required, the inhibition of these genes and proteins could potentially result in the reversal of resistance and lead to the discovery of more effective therapies for breast, ovarian and other cancers.

\section{Acknowledgements}

We appreciate the technical expertise of Dr Wei Chu, Mr. Christian Tovar, Ms. Violeta Adames, Ms. Markella Kordoyanni and Ms. Urmi Bhatt.

\section{References}

1. Alroy I and Yarden Y: The ErbB signaling network in embryogenesis and oncogenesis: signal diversification through combinatorial ligand-receptor interactions. FEBS Lett 410: 83-86, 1997.

2. Olayioye MA, Neve RM, Lane HA and Hynes NE: The ErbB signaling network: receptor heterodimerization in development and cancer. EMBO J 19: 3159-3167, 2000.

3. Slamon DJ, Godolphin W, Jones LA, Holt JA, Wong SG, Keith DE, Levin WJ, Stuart SG, Udove J, Ullrich A, et al: Studies of the HER-2/neu proto-oncogene in human breast and ovarian cancers. Science 244: 707-712, 1989.

4. Ross JS, Slodkowska EA, Symmans WF, Pusztai L, Ravdin PM and Hortobagyi GN: The HER-2 receptor and breast cancer: ten years of targeted anti-HER-2 therapy and personalized medicine. Oncologist 14: 320-368, 2009.

5. Dawood S, Broglio K, Buzdar AU, Hortobagyi GN and Giordano SH: Prognosis of women with metastatic breast cancer by HER 2 status and trastuzumab treatment: an institutional-based review. J Clin Oncol 28: 92-98, 2010.

6. Bookman MA, Darcy KM, Clarke-Pearson D, Boothby RA and Horowitz IR: Evaluation of monoclonal anti-HER2 antibody, trastuzumab, in patients with recurrent or refractory ovarian or primary peritoneal carcinoma with overexpression of HER2: a phase II trial of the Gynecologic Oncology Group. J Clin Oncol 21: 283-290, 2003

7. McAlpine JN, Wiegand KC, Vang R, Ronnett BM, Adamiak A, Köbel M, Kalloger SE, Swenerton KD, Huntsman DG, Gilks CB and Miller DM: HER2 overexpression and amplification is present in a subset of ovarian mucinous carcinomas and can be targeted with trastuzumab therapy. BMC Cancer 9: 433, 2009. 
8. Slamon DJ, Leyland-Jones B, Shak S, Fuchs H, Paton V, Bajamonde A, Fleming T, Eiermann W, Wolter J, Pegram M, Baselga $\mathbf{J}$ and Norton L: Use of chemotherapy plus a monoclonal antibody against HER2 for metastatic breast cancer that overexpresses HER2. N Engl J Med 344: 783-792, 2001.

9. Cobleigh MA, Vogel CL, Tripathy D, Robert NJ, Scholl S, Fehrenbacher L, Wolter JM, Paton V, Shak S, Lieberman G and Slamon DJ: Multinational study of the efficacy and safety of humanized anti-HER 2 monoclonal antibody in women who have HER2-overexpressing metastatic breast cancer that has progressed after chemotherapy for metastatic disease. J Clin Oncol 17: 2639-2648, 1999.

10. Romond EH, Perez EA, Bryant J Suman VJ, Geyer CE Jr, Davidson NE, Tan-Chiu E, Martino S, Paik S, Kaufman PA, Swain SM, Pisansky TM, Fehrenbacher L, Kutteh LA, Vogel VG, Visscher DW, Yothers G, Jenkins RB, Brown AM, Dakhil SR, Mamounas EP, Lingle WL, Klein PM, Ingle JN and Wolmark N: Trastuzumab plus adjuvant chemotherapy for operable HER2-positive breast cancer. N Engl J Med 353: 1673-1684, 2005.

11. Perez EA, Romond EH, Suman VJ, Jeong JH, Davidson NE, Geyer CE Jr, Martino S, Mamounas EP, Kaufman PA and Wolmark N: Four-year follow-up of trastuzumab plus adjuvant chemotherapy for operable human epidermal growth factor receptor 2-positive breast cancer: joint analysis of data from NCCTG N9831 and NSABP B-31. J Clin Oncol 29: 3366-3373, 2011.

12. Smith I, Procter M, Gelber RD, Guillaume S, Feyereislova A, Dowsett M, Goldhirsch A, Untch M, Mariani G, Baselga J, Kaufmann M, Cameron D, Bell R, Bergh J, Coleman R, Wardley A, Harbeck N, Lopez RI, Mallmann P, Gelmon K, Wilcken N, Wist E, Sánchez Rovira P and Piccart-Gebhart MJ: 2-year follow-up of trastuzumab after adjuvant chemotherapy in HER2-positive breast cancer: a randomised controlled trial. Lancet 369: 29-36, 2007.

13. Slamon D, Eiermann W, Robert N, Pienkowski T, Martin M, Press M, Mackey J, Glaspy J, Chan A, Pawlicki M, Pinter T, Valero V, Liu MC, Sauter G, von Minckwitz G, Visco F, Bee V, Buyse M, Bendahmane B, Tabah-Fisch I, Lindsay MA, Riva A and Crown J: Adjuvant trastuzumab in HER2-positive breast cancer. N Engl J Med 365: 1273-1283, 2011.

14. Bang YJ, Van Cutsem E, Feyereislova A, Chung HC, Shen L, Sawaki A, Lordick F, Ohtsu A, Omuro Y, Satoh T, Aprile G, Kulikov E, Hill J, Lehle M, Rüschoff J and Kang YK: Trastuzumab in combination with chemotherapy versus chemotherapy alone for treatment of HER2-positive advanced gastric or gastro-oesophageal junction cancer (ToGA): a phase 3 , open-label, randomised controlled trial. Lancet 376: 687-697, 2010.

15. Spector NL and Blackwell KL: Understanding the mechanisms behind trastuzumab therapy for human epidermal growth factor receptor 2-positive breast cancer. J Clin Oncol 27: 5838-5847, 2009.

16. Albanell $\mathrm{J}$ and Baselga $\mathrm{J}$ : Unraveling resistance to trastuzumab (Herceptin): insulin-like growth factor-I receptor, a new suspect. J Natl Cancer Inst 93: 1830-1832, 2001.

17. Nahta R, Takahashi T, Ueno NT, Hung MC and Esteva FJ: p27 Kipl down-regulation is associated with trastuzumab resistance in breast cancer cells. Cancer Res 64: 3981-3986, 2004.

18. Nagata Y, Lan KH, Zhou X, Tan M, Esteva FJ, Sahin AA, Klos KS Li P, Monia BP, Nguyen NT, Hortobagyi GN, Hung MC and Yu D: PTEN activation contributes to tumor inhibition by trastuzumab, and loss of PTEN predicts trastuzumab resistance in patients. Cancer Cell 6: 117-127, 2004.

19. Nagy P, Friedländer E, Tanner M, Kapanen AI, Carraway KL, Isola J and Jovin TM: Decreased accessibility and lack of activation of ErbB2 in JIMT-1, a Herceptin-resistant, MUC4-expressing breast cancer cell line. Cancer Res 65: 473-482, 2005.

20. Dhillon J, Astanehe A, Lee C, Fotovati A, Hu K and Dunn SE: The expression of activated Y-box binding protein-1 serine 102 mediates trastuzumab resistance in breast cancer cells by increasing CD 44+ cells. Oncogene 29: 6294-6300, 2010

21. Zhang S, Huang WC, Li P, Guo H, Poh SB, Brady SW, Xiong Y, Tseng LM, Li SH, Ding Z, Sahin AA, Esteva FJ, Hortobagyi GN and $\mathrm{Yu}$ D: Combating trastuzumab resistance by targeting SRC, a common node downstream of multiple resistance pathways. Nat Med 17: 461-469, 2011
22. Fernandes H, Cohen S and Bishayee S: Glycosylation-induced conformational modification positively regulates receptorreceptor association: a study with an aberrant epidermal growth factor receptor (EGFRvIII/DeltaEGFR) expressed in cancer cells. J Biol Chem 276: 5375-5383, 2001.

23. Meric F, Lee WP, Sahin A, Zhang H, Kung HJ and Hung MC Expression profile of tyrosine kinases in breast cancer. Clin Cancer Res 8: 361-367, 2002.

24. Unger MA, Rishi M, Clemmer VB, Hartman JL, Keiper EA, Greshock JD, Chodosh LA, Liebman MN and Weber BL: Characterization of adjacent breast tumors using oligonucleotide microarrays. Breast Cancer Res 3: 336-341, 2001.

25. Raponi M, Belly RT, Karp JE, Lancet JE, Atkins D and Wang Y: Microarray analysis reveals genetic pathways modulated by tipifarnib in acute myeloid leukemia. BMC Cancer 4: 56, 2004.

26. Sliwkowski MX, Lofgren JA, Lewis GD, Hotaling TE, Fendly BM and Fox JA: Nonclinical studies addressing the mechanism of action of trastuzumab (Herceptin). Semin Oncol 26 (Suppl): 60-70, 1999.

27. Schroeder JA, Thompson MC, Gardner MM and Gendler SJ: Transgenic MUC1 interacts with epidermal growth factor receptor and correlates with mitogen-activated protein kinase activation in the mouse mammary gland. J Biol Chem 276: 13057-13064, 2001.

28. Nielsen DL, Andersson M and Kamby C: HER2-targeted therapy in breast cancer. Monoclonal antibodies and tyrosine kinase inhibitors. Cancer Treat Rev 35: 121-136, 2009.

29. du Manoir JM, Francia G, Man S, Mossoba M, Medin JA, Viloria-Petit A, Hicklin DJ, Emmenegger U and Kerbel RS: Strategies for delaying or treating in vivo acquired resistance to trastuzumab in human breast cancer xenografts. Clin Cancer Res 12: 904-916, 2006.

30. Fessler SP, Wotkowicz MT, Mahanta SK and Bamdad C: MUC1* is a determinant of trastuzumab (Herceptin) resistance in breast cancer cells. Breast Cancer Res Treat 118: 113-124, 2009.

31. Valabrega G, Capellero S, Cavalloni G, Zaccarello G, Petrelli A, Migliardi G, Milani A, Peraldo-Neia C, Gammaitoni L, Sapino A, Pecchioni C, Moggio A, Giordano S, Aglietta M and Montemurro F: HER2-positive breast cancer cells resistant to trastuzumab and lapatinib lose reliance upon HER2 and are sensitive to the multitargeted kinase inhibitor sorafenib. Breast Cancer Res Treat 130: 29-40, 2011.

32. Ramanathan RK, Hwang JJ, Zamboni WC, Sinicrope FA, Safran H, Wong MK, Earle M, Brufsky A, Evans T, Troetschel M, Walko C, Day R, Chen HX and Finkelstein S: Low overexpression of HER-2/neu in advanced colorectal cancer limits the usefulness of trastuzumab (Herceptin) and irinotecan as therapy. A phase II trial. Cancer Invest 22: 858-865, 2004.

33. Pietras RJ, Fendly BM, Chazin VR, Pegram MD, Howell SB and Slamon DJ: Antibody to HER-2/neu receptor blocks DNA repair after cisplatin in human breast and ovarian cells. Oncogene 9: 1829-1838, 1994.

34. Ritter CA, Bianco R, Dugger T, Forbes J, Qu S, Rinehart C, King W and Arteaga CL: Mechanisms of resistance development against trastuzumab (Herceptin) in an in vivo breast cancer model. Int J Clin Pharmacol Ther 42: 642-643, 2004.

35. O'Brien NA, Browne BC, Chow L, Wang Y, Ginther C, Arboleda J, Duffy MJ, Crown J, O'Donovan N and Slamon DJ: Activated phosphoinositide 3-kinase/AKT signaling confers resistance to trastuzumab but not lapatinib. Mol Cancer Ther 9: 1489-1502, 2010.

36. Scheuer W, Freiss T, Burtscher H, Bossenmaier B, Endl J and Hasmann M: Strongly enhanced antitumor activity of trastuzumab and pertuzumab combination treatment on HER2-positive human xenograft tumor models. Cancer Res 69: 9330-9336, 2009.

37. Vogel CL, Cobleigh MA, Tripathy D, Gutheil JC, Harris LN, Fehrenbacher L, Slamon DJ, Murphy M, Novotny WF, Burchmore M, Shak S, Stewart SJ and Press M: Efficacy and safety of trastuzumab as a single agent in first-line treatment of HER2-overexpressing metastatic breast cancer. J Clin Oncol 20: 719-726, 2002

38. Reim F, Dombrowski Y, Ritter C, Buttmann M, Häusler S, Ossadnik M, Krockenberger M, Beier D, Beier CP, Dietl J, Becker JC, Hönig A and Wischhusen J: Immunoselection of breast and ovarian cancer cells with trastuzumab and natural killer cells: selective escape of CD $44^{\text {high }} / \mathrm{CD} 24^{\text {low }} / \mathrm{HER} 2^{\text {low }}$ breast cancer stem cells. Cancer Res 69: 8058-8066, 2009.

39. Packer LM, Williams SJ, Callaghan S, Gotley DC and McGuckin MA: Expression of the cell surface mucin gene family in adenocarcinomas. Int J Oncol 25: 1119-1126, 2004. 
40. Scibetta AG, Albanese I, Morris J, Cooper L, Downward J, Rowe P and Taylor-Papadimitriou J: Regulation of MUC1 expression in human mammary cell lines by the c-ErbB2 and ras signaling pathways. DNA Cell Biol 20: 265-274, 2001.

41. Hollingsworth MA and Swanson BJ: Mucins in cancer: protection and control of the cell surface. Nat Rev Cancer 4 45-60, 2004.

42. Li Y, Kuwahara H, Ren J, Wen G and Kufe D: The c-Src tyrosine kinase regulates signaling of the human DF3/MUC1 carcinomaassociated antigen with GSK3 beta and beta-catenin. J Biol Chem 276: 6061-6064, 2001.

43. Baselga J, Gelmon KA, Verma S, Wardley A, Conte P, Miles D, Bianchi G, Cortes J, McNally VA, Ross GA, Fumoleau P and Gianni L: Phase II trial of pertuzumab and trastuzumab in patients with human epidermal growth factor receptor 2-positive metastatic breast cancer that progressed during prior trastuzumab therapy. J Clin Oncol 28: 1138-1144, 2010.

44. Krop IE, LoRusso O, Miller KD, Modi S, Yardley D, Rodriguez G, Lu M, Burrington B, Agresta S and Rugo H: A phase 2 study of the HER 2 antibody-drug conjugate trastuzumab-DM1 (TDM-1) in patients (PTS) with HER2-positive metastatic breast cancer (MBC) previously treated with trastuzumab, lapatinib, and chemotherapy [abstract 2770]. Ann Oncol 21 (Suppl 8): viii97, 2010 .
45. Burris HA III, Rugo HS, Vukelja SJ, Vogel CL, Borson RA, Limentani S, Tan-Chiu E, Krop IE, Michaelson RA, Girish S, Amler L, Zheng M, Chu YW, Klencke B and O'Shaughnessy JA: Phase II study of the antibody drug conjugate trastuzumab-DM1 for the treatment of human epidermal growth factor receptor 2 (HER2)-positive breast cancer after prior HER2-directed therapy. J Clin Oncol 29: 398-405, 2011.

46. Konecny GE, Pegram MD, Venkatesan N, Finn R, Yang G, Rahmeh M, Untch M, Rusnak DW, Spehar G, Mullin RJ, Keith BR, Gilmer TM, Berger M, Podratz KC, Slamon DJ: Activity of the dual kinase inhibitor lapatinib (GW572016) against HER-2-overexpressing and trastuzumab-treated breast cancer cells. Cancer Res 66: 1630-1639, 2006.

47. Geyer CE, Forster J, Lindquist D, Chan S, Romieu CG, Pienkowski T, Jagiello-Gruszfeld A, Crown J, Chan A, Kaufman B, Skarlos D, Campone M, Davidson N, Berger M, Oliva C, Rubin SD, Stein S and Cameron D: Lapatinib plus capecitabine for HER2-positive advanced breast cancer. N Engl J Med 355: 2733-2743, 2006. 